
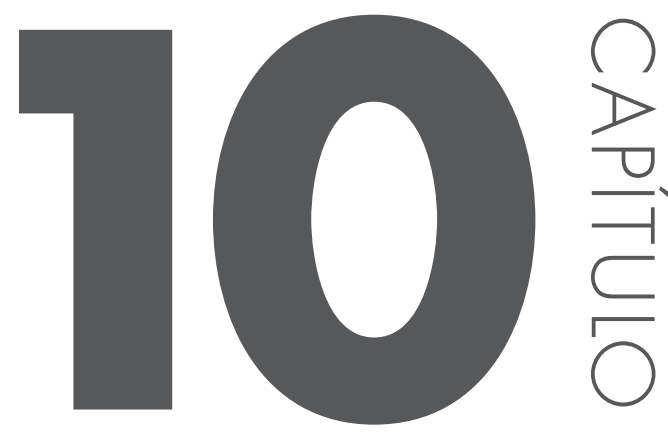

\title{
INVESTIMENTO ESTATAL NA INFRAESTRUTURA PORTUÁRIA BRASILEIRA
}

Matheus C. R. Barros (FACAMP); Luiz M. de Niemeyer N. (PUC-SP)

\section{RESUMO}

O presente artigo tem como objetivo analisar a importância de se investir na infraestrutura de transporte marítimo do país, dado que o mesmo é a principal porta de entrada e saída da economia brasileira. O problema, porém, reside no fato de que há uma grande ineficiência logística nas operações portuárias, explicada, por sua vez, pela carência de investimentos realizados no setor entre o período de 1980 a 2006. Diante disso, é preciso que haja uma mudança no marco regulatório vigente em prol da maior participação do Estado junto ao setor privado.

Palavras-chave: Infraestrutura, investimentos, logística, portos, Estado, setor privado. 


\section{INTRODUÇÃO}

Esse artigo tem como objetivo analisar o investimento estatal na infraestrutura portuária no período entre 1980 a 2006 de modo a verificar a hipótese de que a ausência desses investimentos teve como consequência a ineficiência logística do setor perante as novas exigências do comércio internacional. O Brasil, por exemplo, durante o boom de exportação de commodities que se iniciou em 2005 ficou muito aquém neste tipo de infraestrutura.

É de extrema importância se analisar a conjuntura logística portuária atual do Brasil. O modal marítimo é a principal porta de entrada e saída das relações comerciais do país com o exterior. A competitividade do país a nível regional e internacional depende muito da eficiência das operações nesse setor.

Esse estudo terá duas seções. A primeira consiste em uma análise da importância do setor portuário para o desempenho da economia brasileira. A segunda irá discutir o investimento público no setor portuário brasileiro no período entre 1980 a 2006 de modo a analisar a qualidade do investimento realizado em infraestrutura

\section{A IMPORTÂNCIA DE SE INVESTIR NO SETOR PORTUÁRIO BRASILEIRO}

O Brasil tem 34 Portos Públicos, 16 têm sua operação concedida à administração de governos estaduais e municipais e 18 são administrados por sete Companhias DOCAS Federais, sociedades de economia mista, cujo acionista majoritário é o Governo Federal1, ligadas, portanto, diretamente à Secretaria de Portos (SEP). Além desses, estão em operação atualmente 101 Terminais de Uso Privativo (DIEESE, 2012, p.2)

Atualmente o Brasil possui um sistema portuário que movimenta anualmente cerca de 700 milhões de toneladas das mais variadas mercadorias e é responsável, sozinho, por mais de $88 \%$ das exportações e $85 \%$ das importações do país. Esse sistema é constituído por 34 portos públicos, entre marítimos e fluviais..Os portos fluviais e lacustres pertencem ao domínio administrativo do Ministério dos Transportes. (SECRETARIA DE PORTOS, 2010)

A título de comparação, o sistema portuário da China, considerado um dos maiores do mundo, é composto por 419 portos marítimos e 355 fluviais, contabilizando uma movimentação de aproximadamente 8 bilhões de toneladas ao ano. Segundo relatório elaborado pelo instituto "Chinese Academy of Sciences”, dos 20 maiores portos mundiais, 11 estão localizados na China, o que 
reflete, portanto, a importância que esse modal marítimo possui no desempenho econômico de qualquer país.

De modo a ilustrar a disparidade portuária do Brasil com relação aos sistemas portuários de classe mundial, segue abaixo uma tabela comparativa entre o Porto de Santos, considerado o maior do país, e o porto de Roterdã, principal complexo de carga da Europa.

\begin{tabular}{|c|c|c|}
\hline Dados & Porto de Santos & Porto de Roterdã \\
\hline $\begin{array}{c}\text { Quantidade } \\
\text { movimentada de } \\
\text { mercadorias }\end{array}$ & 83.194 .000 toneladas & 386.957 .000 toneladas \\
\hline $\begin{array}{c}\text { Número de } \\
\text { atracações recebidas } \\
\text { anualmente }\end{array}$ & 5.731 atracações & 33.352 atracações \\
\hline $\begin{array}{c}\text { Profundidade do } \\
\text { calado do canal de } \\
\text { acesso }\end{array}$ & 14 metros & 20 metros \\
\hline $\begin{array}{l}\text { Tempo Médio de } \\
\text { espera do navo para } \\
\text { atracação }\end{array}$ & 11 horas & 3 horas \\
\hline Faturamento & RS 498,8 milhões & RS 1,15 billhoes \\
\hline \multicolumn{3}{|l|}{ Fonte: BRITO, 2010} \\
\hline
\end{tabular}

Com tamanha diferença, fica claro que investir na infraestrutura portuária do Brasil se torna cada vez mais importante pois os portos são a principal porta de entrada e saída das relações comerciais do país de modo que sua competitividade a nível regional e internacional depende muito da eficiência das operações nesse setor.

Essa demanda por investimentos no setor se torna ainda mais evidente frente ao aumento das trocas comercias do Brasil com o mundo. Segundo dados do Ministério do Desenvolvimento Indústria e Comércio Exterior (MDIC), o volume das exportações do país saltou, no período entre 2000 e 2010, de cerca de U\$ 55 bilhões para U\$ 201 bilhões. Ou seja, houve um crescimento de 266\% das exportações brasileiras em 10 anos, sendo que $88 \%$ dessas mercadorias exportadas foram via portos. Já as importações aumentaram de U\$ 52 bilhões, 
em 2000, para U\$ 182 bilhões, em 2010, sendo que 88,85\% foi importado via portos.

Os dois gráficos que seguem ilustram a evolução das exportações do país na última década bem como a importância dos portos no seu escoamento.

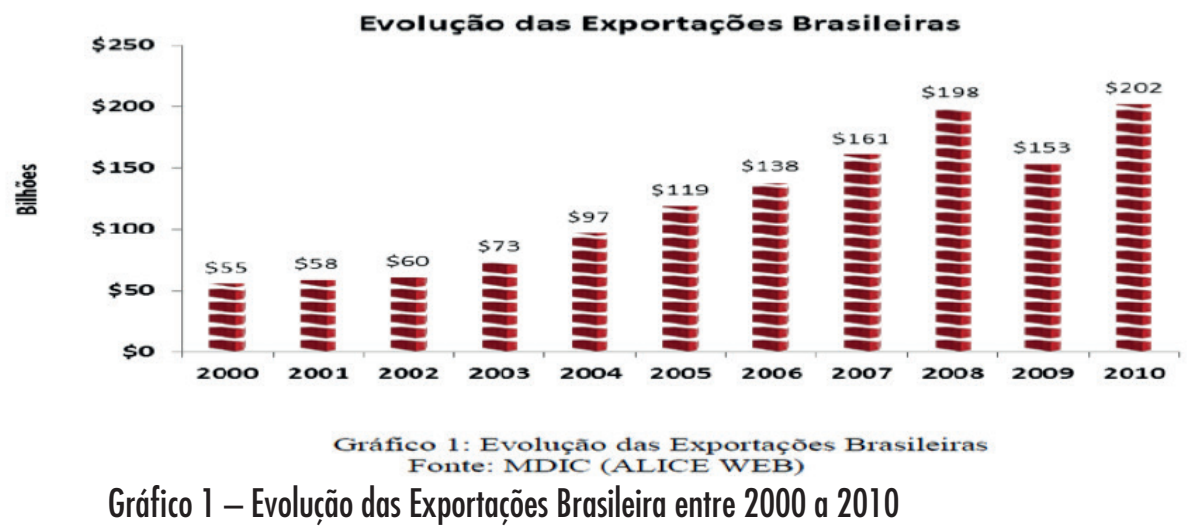

Participação das Vias de Transporte (em US\$)

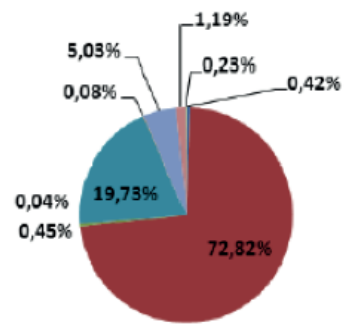

- LINHA DE TRANSMISSAO = MARITIMA

= FLUVIAL

- AEREA

- RODOVIARIA

I- MEIOS PROPRIOS

Gráfico 2: Participação em US\$

Fonte: MDIC (ALICE WEB)
Participação das Vias de Transporte

(emton)
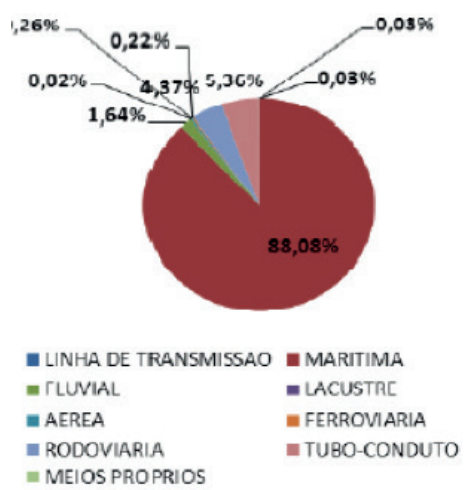

Gráfico 3: Participação em ton Fonte- MTIC (AT.ICF. WF.B)

Gráfico 2 - Participação de cada via de transporte nas exportações do Brasil em 2010

Como visto, o transporte marítimo domina a matriz de transporte brasileira e, portanto, deve ser visto como o elo central da cadeia logística do país. O problema, porém, reside no fato que há três grandes gargalos que impedem uma maior eficácia das suas operações. 
O primeiro gargalo presente em todos os portos brasileiros diz respeito a profundidade do calado. Melhor explica Pedro Brito, ex-ministro da Secretaria de Portos (SEP):

"a profundidade do canal do cais de Santos não era a mais adequada, e isso fazia com que, em vez de receber navios de 8.600 TEUs ${ }^{1}$, só recebesse navios de 4.800 TEUs, o que reduzia a eficiência pela metade. Em vez de operar um navio grande, Santos precisava operar dois ou três navios menores para movimentar o mesmo volume de carga;ou, em vez de operar um navio grande totalmente carregado, operava uma navio grande carregado pela metade. Isso é ineficiência na veia” (BRITO, 2010, p.98).

O segundo gargalo é encontrado nas deficiências das instalações nos terminais dos portos brasileiros no que diz respeito aos equipamentos de infraestrutura e berços de atracação com comprimento adequado para atender os navios que estão cada vez maiores.

O terceiro gargalo é encontrado nos acessos aos portos por meio de ferrovias, rodovias, e hidrovias. Isso porque a matriz de transporte de acesso aos portos é dominada pelo rodoviário que, por sua vez, é o mais caro e ineficiente dentre os modais. Como se pode observar na Tabela 2, para se transportar 6 mil toneladas são necessários 172 carretas enquanto que um navio de cabotagem carrega a mesma quantia ou 2,9 comboios (86 vagões cheios).

\begin{tabular}{|l|l|l|l|}
\hline Tabela 2 - Equivalência de Modais \\
\hline Modal & Hidrovia & Ferrovia & Rododvia \\
\hline & $\begin{array}{l}\text { 1 navio de cabotagem ou } \\
\text { barcaça }\end{array}$ & $\begin{array}{l}2,9 \text { comboios (86 vagões } \\
\text { cheios) }\end{array}$ & 172 carretas \\
\hline Capacidade da carga & 6000 toneladas & 6000 toneladas & 6000 toneladas \\
\hline Comprimento total & 150 metros & 1,7 Kilômetros & 26 Kilômetros \\
\hline Fonte: BRITO, 2010
\end{tabular}

Ou seja, é preciso criar alternativas para evitar que o caminhão se desloque até o cais do porto para levar e embarcar cargas. O Brasil possui um amplo potencial hidroviário com mais de 40 mil Kilômetros de vias fluviais que não são aproveitadas, e, portanto, deve promover uma maior acessibilidade aos portos por hidrovias, que é menos custoso do que o rodoviário. 
De acordo com BRITO (2010),

"Qualquer porto importante do mundo, como Roterdã, por
exemplo, tem sua acessibilidade garantida pelo transporte fluvial,
por meio de barcaças que levam e retiram cargas" (Ibidem, 2010,
p.92).

Segundo Fleury (2011), a presença desses gargalos e a consequente ineficiência portuária acarretam em um acréscimo de $7 \%$ no custo dos produtos exportados pelo Brasil, o que representa, portanto, uma grande perda de competitividade no mercado internacional.

Segundo Pedro Brito, hoje, no Brasil, é preciso 5,4 dias em média para liberar uma carga (por exemplo, um contêiner), enquanto em que nos portos mais eficientes do mundo esse tempo é de 1 dia senão menos.

De acordo com o estudo do Banco Mundial, denominado The Logistics Performance Index and Its Indicators iniciado em 2007, o Desempenho

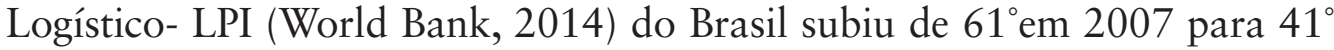
lugar em 2010. Todavia, em 2012 na classificação era de $45^{\circ}$ lugar e em $201465^{\circ}$. Estamos longe de alcançar o topo da tabela. Isto se deve, entre outras coisas, ao impacto negativo da burocracia aduaneira e fiscal. Isto gera pouca eficiência no processo de liberação e desembaraço de transações nas alfândegas e outras agências de controle de fronteiras. Isto gera também outros obstáculos que dificultam o processo de embarque de mercadorias exportadas.

A Tabela 3 mostra os países que possuem as melhores infraestruturas logísticas do mundo e o destaque é a Alemanha, que se tornou país líder em logística mundial em 2010. Apenas para citar como exemplo de investimento, os alemães construíram um canal artificial que conecta o rio Reno ao rio Danúbio. Este canal possui 172 quilômetros de comprimento, 60 metros de largura e 4 metros de profundidade. A navegação ocorre o ano inteiro devido a existência de suas 17 eclusas. É por esse canal que um navio que atraca no Porto de Roterdã, situado no norte da Europa, pode ter sua carga transportada sua carga até o Mar Negro, na outra ponta do continente, já que os rios dos países da região são todos conectados por canais que se estendem por aproximadamente 3.800 quilômetros. 
Tabela 3 - Líderes do LPI (Desempenho Logístico)

\begin{tabular}{|c|c|c|c|c|c|c|}
\hline & \multicolumn{3}{|c|}{ AVALIAÇÃO DE 2010} & \multicolumn{3}{|c|}{ AVALIAC̣ÃO DE 2007} \\
\hline & $\begin{array}{c}\text { LPI } \\
\text { CLASSIFICAÇÃOO }\end{array}$ & LPI ÍNDICE & $\begin{array}{l}\text { \% DO MELHOR } \\
\text { COLOCADO }\end{array}$ & $\begin{array}{c}\text { LPI } \\
\text { CLASSIFICAÇÃOO }\end{array}$ & LPI ÍNDICE & $\begin{array}{l}\text { \% DO MELHOR } \\
\text { COLOCADO }\end{array}$ \\
\hline ALEMANHA & 1 & 4,11 & 100,0 & 3 & 4,10 & 97,1 \\
\hline CINGAPURA & 2 & 4,09 & 99,2 & 1 & 4,19 & 100,0 \\
\hline SUÉCIA & 3 & 4,08 & 98,8 & 4 & 4,08 & 96,4 \\
\hline HOLANDA & 4 & 4,07 & 98,5 & 2 & 4,18 & 99,6 \\
\hline LUXEMBURGO & 5 & 3,98 & 95,7 & 23 & 3,54 & 79,5 \\
\hline SUÍÇA & 6 & 3,97 & 95,5 & 7 & 4,02 & 94,5 \\
\hline JAPÃO & 7 & 3,97 & 95,2 & 6 & 4,02 & 94,8 \\
\hline REINO UNIDO & 8 & 3,95 & 94,9 & 9 & 3,99 & 93,8 \\
\hline BÉlGICA & 9 & 3,94 & 94,5 & 12 & 3,89 & 90,7 \\
\hline NORUEGA & 10 & 3,93 & 94,2 & 16 & 3,81 & 88,1 \\
\hline BRASIL & 41 & 3,20 & 70,6 & 61 & 2,75 & 54,9 \\
\hline
\end{tabular}

Fonte: World Bank, 2010, p. viii

Diante dessas disparidades, pode-se afirmar que o Brasil necessita de uma reformulação no sistema portuário vigente dado a ineficiência logística do setor perante as novas exigências do comércio internacional. Como o intuito do presente artigo não é apresentar propostas ao setor e sim discutir os motivos que levaram a ineficácia atual, na próxima seção será discutido os investimentos que foram realizados no setor no período entre 1980 a 2006.

\section{UMA ANÁLISE DOS INVESTIMENTOS DO PERÍODO ENTRE 1980 A 2006}

Essa infraestrutura defasada do sistema portuário descrita na seção anterior é consequente de um longo período caracterizado pela carência de investimentos: desde o inicio de 1980 até os anos 2000 o Estado ficou impossibilitado de investir, dado as restrições externas que lhe foram impostas pelo Fundo Monetário Internacional (FMI). A chamada programação financeira do Fundo para países em crise de Balanço de Pagamentos pode ser resumida ao corte nos gastos do governo/déficit público. 
Os cortes no déficit podem envolver e normalmente envolvem cortes no chamado "quase déficit" que abrange entre outras operações os empréstimos das empresas estatais junto ao setor financeiro. Em outras palavras corte nos gastos das empresas estatais. O FMI segue a abordagem monetária do balanço de pagamentos que afirma que corte nos gastos do governo geram superávit no balanço de pagamentos. Além disso, na visão do Fundo os gatos do governo "crowd out" (inibem) os investimentos do setor privado.

$\mathrm{Na}$ década de 80 a economia brasileira teve um desempenho bem diferente daquele que tinha vivenciado nas décadas anteriores, principalmente a dos anos 70 na qual o país obteve um elevado crescimento econômico caracterizado como "milagre econômico" e "IIo PND".

É importante mencionar que enquanto os anos 70 foram marcados por uma crescente absorção dos recursos reais advindos do exterior por meio de recorrentes déficits comerciais. Com a crise da dívida externa que se iniciou em 1982, os anos 80 foram caracterizados por uma continua transferência de recursos reais para o exterior por meio da obtenção de superávits primários. Ou seja, segundo Carneiro (2002), a obrigatoriedade em transferir recursos reais para o exterior para servir a dívida externa criou um constrangimento ao desenvolvimento da economia nacional. Dessa forma, pode-se afirmar que houve uma expressiva redução do nível de investimentos e estagnação do produto per capita.

Essa recessão da década de 80 pode ser explicada devido ao fato de que a compatibilidade entre crescimento e transferência de recursos para o exterior só seria possível se o crescimento ocorresse por meio da ocupação da capacidade produtiva ociosa. Dessa forma, uma vez que a capacidade produtiva existente estivesse totalmente utilizada, o crescimento dependeria do aumento da taxa de investimento, que possua vez, dependeria da ampliação das importações e da diminuição do saldo comercial (CARNEIRO, 2002, pg. 141).

Além disso, é importante destacar que a política de ajuste do período tinha como objetivo reduzir o excesso de dispêndio, ou seja, o déficit em transações correntes. Esse ajuste tinha dois requisitos básicos: a diminuição do déficit público por meio do aumento da poupança doméstica, principalmente por parte do setor público (o principal devedor); e mudança dos preços relativos a fim de aumentar o coeficiente exportado e diminuir o coeficiente importado para, assim, gerar divisas (ibidem, pg.142).

O nível de investimento, por sua vez, se apresentou muito baixo durante a década, evidenciando, portanto, a incompatibilidade entre uma política de transferência de recursos para o exterior e o crescimento sustentado. Um dos motivos que explicam os baixos investimentos no período é a ruptura que 
ocorreu entre os investimentos privados e públicos. Como se pode observar na Tabela 4, houve um declínio dos investimentos do setor produtivo estatal bem como dos investimentos privados (Ibidem, pg.147).

Tabela 4 - Evolução dos Investimentos realizados por agente entre 1981 a 1989

\begin{tabular}{|l|c|c|c|c|c|c|c|c|c|}
\hline \multicolumn{7}{|c|}{ Evolução do investimento por agente 1981-1989 } \\
\hline Período & Total & \multicolumn{2}{|c|}{ Setor Produtivo Estatal } & Administração Pública & \multicolumn{2}{|c|}{ Setor Privado } & \multicolumn{2}{c|}{ Outros } \\
\hline & (\% a.a) & (\% a.a) & (\% do total) & (\% a.a) & (\% do total) & (\% a.a) & (\% do total) & (\% a.a) & (\% do total) \\
\hline $1981-89$ & $-1,4$ & $-7,4$ & 17,8 & 0,1 & 12,5 & 0,0 & 66,9 & $-5,6$ & 2,8 \\
\hline $1981-83$ & $-11,7$ & $-10,8$ & 22,2 & $-12,6$ & 10,8 & $-11,5$ & 64,0 & $-17,8$ & 3,0 \\
\hline $1984-86$ & 10,5 & $-1,0$ & 17,5 & 29,4 & 14,0 & 10,2 & 66,1 & 13,0 & 2,4 \\
\hline $1987-89$ & $-1,6$ & $-10,1$ & 13,5 & $-16,5$ & 13,4 & 2,6 & 70,6 & $-9,6$ & 2,6 \\
\hline Fonte: FlBGE e Sest & & & & & & & \\
\hline
\end{tabular}

Dados copilados por Carneiro, 2002, pg. 147

Ademais, o investimento público realizado na década de 80 , voltado para obras de infraestrutura, obteve um crescimento muito aquém do necessário. Como Carneiro analisa:

É marcado por fortes oscilações cíclicas e pela incapacidade de sustentar patamares elevados em períodos mais longos comparativamente ao investimento privado. $\mathrm{O}$ padrão de ajustamento adotado ao longo da década, que sempre privilegiou o corte de investimentos como mecanismo de ajuste fiscal, e, posteriormente, a crise financeira do setor público, ambos decorrentes da transferência de recursos para o exterior, constituem a origem desse comportamento (Ibidem, pg. 148).

Esse baixo nível de investimentos do setor estatal evidencia a dependência das empresas estatais do financiamento externo para a realização dos seus investimentos. Dessa forma, pode-se afirmar que a escassez desse financiamento bem como a obrigatoriedade de pagar pelo menos a amortização da dívida contraída foram as principais razões da queda dos investimentos no setor. $\mathrm{O}$ investimento privado, por sua vez, obteve o mesmo desempenho culminando, portanto, na ausência de um crescimento sustentado.

Dito isso, fica claro que a construção civil voltada para consecução de obras de infraestrutura, sejam elas nos portos e nos outros modais de transporte do Brasil, obteve um baixo desempenho no período dado. Ou seja, a crise das finanças públicas no Brasil na década de 80 teve como consequência a perda de capacidade o Estado de alocar recursos para expansão e manutenção da infraestrutura. 
Dessa forma, no final da década de 80 os portos brasileiros estavam completamente ultrapassados se comparados aos grandes portos internacionais que, naquele momento, já haviam implementado o contêiner nas suas operações de transporte, possibilitando, assim, uma maior eficácia nas movimentações portuárias: as operações de embarque e desembarque, que antes levavam dias, passaram a ser feitas em horas.

A partir dos anos 90 o Brasil passa a adotar uma política de liberalização econômica implicando, assim, em mudanças importantes em sua pauta do comércio exterior. Esse processo se iniciou durante o governo Collor, porém se consolidou no governo de Fernando Henrique Cardoso.

Durante o mandato de FHC (1995-2002) a Política Industrial de Comércio Exterior (PiCE) lançou o Plano Nacional de Desestatização (PND) e promoveu a implementação de reformas tarifarias bem como de comercio exterior objetivando a diminuição das barreiras as importações.

O PND teve como consequência a expressiva diminuição da Formação Bruta de Capital Fixo (FBK), pois se de um lado o processo de privatização provocou o recuo das taxas de investimento das empresas estatais de outro o espaço não foi ocupado pelo investimento do setor privado como um todo.

Pode-se afirmar que a partir de 1999 a redução da FBK foi ainda mais expressiva dado a implementação de metas fiscais que limitaram o endividamento do setor público. No ano de 1999 os investimentos públicos contabilizaram apenas 1,91\% do PIB, o menor valor desde 1950 até 2006. É importante destacar que a média desses investimentos do período de 1990 até 2002 atingiu apenas 3,22\% do PIB (REIS, 2008).

A autora acima destaca que esse baixo patamar dos investimentos por parte do setor público é resultante de um regime fiscal contracionista como diretriz central da política cambial e do cumprimento das metas e inflação com juros elevados. Esse contexto de juros altos atrelados à diminuição da linha de crédito teve uma grande contribuição para a não substituição do investimento público pelo investimento privado até 2006.

O setor portuário, por sua vez, vivenciou um processo de renovação institucional na década de 90. No ano de 1990, a Empresa de Portos do Brasil S/A - PORTOBRAS, criada em 1975 e símbolo da centralização administrativa do Estado no setor, foi extinta, deixando uma espécie de vazio administrativo no setor portuário. Assim, em 1993 o setor presenciava uma crise institucional, pois, como já mencionado acima, não havia nenhum órgão definido para exercer a administração dos portos. Além disso, era intenso o movimento em prol da modernização das instalações portuárias de modo a retomar o crescimento econômico do país. (MARONE, et al.,s.d.:4-6). 
Assim, em 25 de fevereiro de 1993, é decretada a Lei de Modernização dos Portos (Lei 8.630). Essa lei, ao ter seu conteúdo pautado na questão da exploração dos portos, estabeleceu um novo marco legal ao setor portuário, pois tinha como objetivo descentralizar a administração dos portos bem como promover uma participação da iniciativa privada no setor portuário. Ao ter como proposta a liberalização da atividade portuária, incentivando as operações realizadas por agentes privados, a lei pretendia implementar uma completa modificação na estrutura portuária brasileira (ROCHA; MORATO, s.d.).

Os principais objetivos e expectativas da lei 8.630 são: a) promover uma exploração dos movimentos de operação do setor portuário pelo setor privado; b) modernizar as operações por meio da aquisição de equipamentos mais produtivos pelos agentes privados; c) obter uma redução no tempo de espera e de permanência dos navios nos portos; d) permitir a exploração de cargas de terceiros em terminais de uso privativo que estavam anteriormente limitados às cargas próprias; e) promover o arrendamento das instalações e de terminais a empresas privadas a fim de estimular a concorrência entre terminais e entre portos; f) avaliar o desenvolvimento tecnológico e produtivo no setor de modo a obter uma análise adequada da quantidade de mão de obra utilizada na operação portuária (ROCHA; MORATO, s.d.).

Com o novo marco regulatório o Estado ficou responsável pela manutenção da infraestrutura portuária e o setor privado pela recuperação e manutenção das instalações dos portos, isto é, pela exploração e gestão dos terminais portuários.

A fim de descrever sobre os investimentos públicos e privados realizados no setor portuário durante a década de 90 e anos 2000 é importante mencionar primeiramente quais são suas fontes.

No que diz respeito ao investimos públicos pode-se afirmar que suas principais fontes são a execução orçamentária do Governo Federal e os investimentos estatais, ou seja, as companhias DOCAS. Com relação ao setor privado, a sua principal fonte é o Banco Nacional do Desenvolvimento Econômico e Social (BNDES) já que o mesmo passou a financiar a compra de equipamentos para o setor privado por meio da concessão de crédito intitulada de Financiamento de Máquinas e Equipamentos (FINAME). O BNDES também lançou o Financiamento a Empreendimentos (FINEM) com o objetivo de conceder linhas de crédito para a realização de investimentos em portos e terminais.

Ao observar a evolução dos investimentos no período fica claramente perceptível que o setor de transportes passou a ter maior relevância no cenário econômico, embora ainda represente cerca de 1,15\% do Produto Interno Bruto (PIB) (IPEA, 2010, pg. 17). 
A Tabela 5 demonstra os investimentos totais realizados em transportes incluindo o transporte hidroviário sendo que cerca de 80 por cento é realizado em portos.

Tabela 5 - Desembolsos públicos e privados em infraestrutura 1999-2008 (R\$ milhões)

\begin{tabular}{|c|c|c|c|c|c|c|c|c|c|c|}
\hline Ano & 1999 & 2000 & 2001 & 2002 & 2003 & 2004 & 2005 & 2006 & 2007 & 2008 \\
\hline \multicolumn{11}{|c|}{ Investimento Público } \\
\hline Transportes & 620,36 & 776,01 & $1.037,39$ & $2.480,24$ & $1.091,90$ & $1.025,49$ & $2.453,38$ & $2.443,38$ & $4.484,05$ & $3.009,46$ \\
\hline Setor Portuário & 67,03 & 114,87 & 257,71 & 903,5 & 525,14 & 121,83 & 150,11 & 106,91 & 257,9 & 580,97 \\
\hline $\begin{array}{l}\text { \% Portos em } \\
\text { Transportes }\end{array}$ & $10,80 \%$ & $14,80 \%$ & $24,84 \%$ & $36,43 \%$ & $48,09 \%$ & $11,88 \%$ & $6,12 \%$ & $4,38 \%$ & $5,75 \%$ & $19,30 \%$ \\
\hline \multicolumn{11}{|c|}{ Investimento Privado } \\
\hline Porttólio BNDES & $7.811,34$ & $10.965,17$ & $13.243,94$ & $24.626,50$ & $23.991,10$ & $32.036,01$ & $38.240,05$ & $43.371,33$ & $59.095,96$ & $90.877,90$ \\
\hline Inv. Transportes & $1.115,28$ & $1.051,28$ & $1.532,56$ & $2.616,04$ & $4.245,51$ & $7.174,76$ & $10.713,22$ & $12.668,49$ & $20.209,15$ & $30.339,17$ \\
\hline $\begin{array}{l}\text { Inv Privado em } \\
\text { Portos }\end{array}$ & 11 & 53 & 5,2 & 269,06 & 731,41 & 921,66 & 572,08 & 671,75 & $1.074,00$ & $1.102,50$ \\
\hline $\begin{array}{l}\text { \% Portos em } \\
\text { Transportes } \\
\text { Total setor por- }\end{array}$ & $1,38 \%$ & $0,86 \%$ & $0,87 \%$ & $1,09 \%$ & $3,05 \%$ & $2,88 \%$ & $1,50 \%$ & $1,55 \%$ & $1,82 \%$ & $1,21 \%$ \\
\hline tuário & 175,14 & 209,4 & 372,91 & $1.172,57$ & $1.256,56$ & $1.043,49$ & 722,19 & 778,66 & $1.331,90$ & $1.683,47$ \\
\hline
\end{tabular}

Fonte: Siga Brasil (2009); MPOG/SE/DEST (2009); e BNDES (2009b).

Elaboraçăo: IPEA (DISET/DIRUR).

Dados copilados por Campos Neto, et all (2010), pg 17

O setor portuário, por sua vez, não acompanhou esse mesmo crescimento ascendente do setor de transportes, mantendo um nível de investimentos de aproximadamente $0,06 \%$ do PIB, atingindo seu pico no ano de 2003 quando contabilizou 0,12\% do PIB (Campos Neto, et all. 2009, pg. 7). A principal restrição aos investimentos em infraestrutura para o governo é a fiscal, que se tornou mais crítica com a mudança de modelo de financiamento do setor público pós-constituição de 1988

Ao se comparar o nível de investimentos público e privado em transportes percebe-se que o último investiu, em média, R 900 milhões a mais do que o primeiro no período de 1999 a 2003. Essa diferença só aumentou nos anos seguintes de tal modo que entre 2004 e 2008 o setor privado investiu R\$13,5 bilhões, em média, a mais do que o setor público em transportes (Ibidem, pg. 7). A partir de 2002, os investimentos privados passam a se distanciar das aplicações do governo, chegando a $\mathrm{R} \$ 30$ bilhões apenas em desembolsos do BNDES, contra R\$ 3 bilhões do governo, em 2008.

Com relação aos portos, pode-se afirmar que entre 1999 a 2003 o setor público investiu R\$ 100 milhões, em média, a mais do que o privado. Porém, 
essa situação mudou a partir de 2004, quando o setor privado se tornou o maior investidor do setor portuário.

Um impacto positivo nos investimentos causado pela Lei de Modernização

dos Portos foi que os contratos de serviços portuários de agentes privados passaram a obrigar que esses agentes realizassem investimentos nos portos. No entanto, os investimentos focaramse na melhoria e modernização de instalações, reduzindo custos dos serviços portuários, deixando de lado o processo de integração com os transportes terrestres para reduzir gargalos de acesso. As áreas de armazenagem também foram negligenciadas e, apesar da redução dos custos, a estrutura tarifária não melhorou, diminuindo os possíveis ganhos (REIS, 2008b) apud (IPEA, 2010 pg.18)

Essa maior participação da iniciativa privada nas operações portuárias trouxe avanços em termos de operacionalidade logística: a) aumento de produtividade na movimentação de contêineres; b) redução de aproximadamente $85 \%$ no tempo de espera dos navios para atracação; porém, não foram suficientes para que os portos se tornassem competitivos frente às novas exigências do comercio internacional, permanecendo, ainda, como visto anteriormente, graves gargalos logísticos que entravam o desenvolvimento portuário do país.

Como visto na Tabela 5, a participação dos investimentos em portos no total investido em transportes está muito aquém do necessário para que o país tenha uma operacionalidade logística portuária efetiva. Em média, os portos receberam apenas $2,8 \%$ dos investimentos públicos direcionados para o transporte e $5,1 \%$ dos investimentos privados.

$\mathrm{Na}$ tentativa de reduzir as deficiências da infraestrutura nacional, o governo federal lançou em 2007 o Programa de Aceleração do Crescimento (PAC). Apenas no setor de Logística, o orçamento inicial do PAC previa aporte de R\$ 58 bilhões entre 2007 e 2010. Deste total, cerca de 7 por cento se destinaram aos portos e hidrovias. $\mathrm{O}$ investimento previsto respectivamente para portos e hidrovias era de R $\$ 2443$ milhões e $\mathrm{R} \$ 1324$ milhões. O investimento realizado até outubro de 2010 foram respectivamente, R 784 milhões e R\$ 1010 milhões. (Fleury,s.d., pg. 9). 


\section{CONCLUSÃO}

A partir do breve estudo realizado acima, pode-se afirmar que o Brasil precisa melhorar muito a competitividade do seu setor portuário para que, ao menos, fique próximo dos parâmetros internacionais.

Na primeira seção foi apresentado a importância desse modal para a economia brasileira bem como os gargalos que alavancam sua eficiência logística. Com o intuito de mostrar as razões pela qual o setor se encontra defasado, a segunda seção se delimitou em analisar os investimentos realizados em infraestrutura no período de 1980 a 2005 assim como as propostas do PAC de 2007. Constatouse que o nível do investimento estatal em infraestrutura tem se mantido muito aquém do necessário para se estruturar um setor portuário competitivo,

Essa baixa participação do Estado na década de 80 estava totalmente atrelada a escassez de financiamento externo e as obrigatoriedades impostas pelos diversos acordos com o FMI e amortizações da dívida externa contraída principalmente na década de 70. Esse cenário se manteve na década de 90 de tal forma que a média dos investimentos públicos do período de 1990 até 2002 atingiu apenas 3,22\% do PIB. Se por um lado não houve investimento por parte do Estado, também não houve por parte do setor privado, dado que o mesmo também investiu muito pouco em portos.

Pode-se dizer, portanto, que o setor portuario nacional, bem como a infraestrutura de transporte em geral, ficou a a margem do desensevolvimento nacional, culminando no atual cenário de estrangulamento das vias que escoam a produçao brasileira.

Diante disso, é preciso que seja feita uma mudança no marco regulatório portuário do país de tal modo que o Estado se torne mais ativo na economia e, então, crie estímulos para a participação direta da iniciativa privada em investimentos. As restrições externas impostas ao Estado para investir em infraestrutura e a consequente a ineficiência logística do setor portuário figuram o quanto a participação estatal é importante para o desenvolvimento da economia, tanto por meio de incentivo a investimentos de terceiros quanto nos investimentos diretos.

Junto a isso, com a privatização das operações portuárias após a Lei da Modernização dos Portos, em 1993, e a consequente melhoria nas mesmas, ainda que tímidas perante aos patamares internacionais, a discussão que vêm à tona diz respeito à possibilidade de construção de portos inteiramente privados. $\mathrm{Ou}$ seja, a iniciativa privada ficaria responsável não só pelas operações portuárias como também pela ampliação da infraestrutura dos portos brasileiros por meio de contratos de licitação. 
Essa proposta está baseada na existência de uma forte complementariedade entre investimento público e privado em infraestrutura de tal modo que o primeiro cumpriria o papel de gerar uma demanda por gastos do segundo por meio da criação de um ambiente propício.

Dessa forma, o Estado cumpre um papel central de amenizar a incerteza dos agentes privados quanto à rentabilidade de seus investimentos no longo prazo, ou seja, deve implantar uma política econômica ativa voltada para o aumento da expectativa de rendimento futuro do empresariado brasileiro.

Como o intuito desse artigo não é se aprofundar nas soluções propostas ao setor, tem-se, no momento, que antes de implantar qualquer reforma o Brasil necessita compreender que investir em infraestrutura é essencial para aumentar a competividade sistêmica e para promover um novo ciclo de crescimento e, por isso, o investimento na rede de transportes se tornou condição primária para a competividade do país no cenário internacional. 


\section{ABSTRACT}

This article has the aim of analyzing the importance of the investment in maritime transport of the country as it is the main way of imports and exports of the brazilian economy. Despite of that, the lack of investments during the period between 1980 and 2006 has brought to a logistical inefficiency of the port's operacionality. Considering that, the Brazilian State must be more active at the economy by investing directly at port's infrastructure and creating conditions to the private investment.

Keywords: Infrastructure, investments, logistic, ports, State, private sector. 


\section{REFERÊNCIAS}

BRITO, Pedro. Muito a Navegar Uma Análise Logística dos Portos Brasileiros. Rio de Janeiro: Topbooks, 2010.

CARNEIRO, Ricardo. Desenvolvimento em crise: a economia brasileira no último quarto do século XX. São Paulo: Editora Unesp, IE - Unicamp, 2002.

DIEESE, Programa de Investimento em Logísitica: Portos, 2012,Disponivel em http://www.fnportuarios.org. br/wp-content/uploads/2013/01/Coment\%C3\%Alrios-sobre-a-MP-595_20_12_2012.pdf. Acessado: Abril de 2015 FLEURY, Paulo Fernando, Infraestrutura -sonhos e realidade. Disponível em: http://cemacro.fgv.br/sites/ cemacro.fgv.br/files/Paulo\%20Fernand0\%20Fleury\%20\%20Infraestrutura.pdf. Acessado: Abril de 2015

IPEA, Portos Brasileiros: Diagnóstico, Políticas e Perspectivas, IPEA 2010, Disponível em: http://www. feaduaneiros.org.br/site.FNDA/downloads/Comunicado\%20d0\%201PEA\%20n\%C2\%BA\%2048.pdf. Acessado: Abril de 2015

MARONE, et al. Os portos brasileiros frente à ciência, tecnologia e inovaccão: Um novo desafio para a sociedade. Disponível em: www.cgee.org.br/atividades/redirect.php?idProduto=2150. Acessado: Jul. 2013.

MDIC. Ministério do Desenvolvimento, Indústria e Comércio Exterior. Disponível em: < http://aliceweb2.mdic.gov.br/>. Acessado: Maio. 2013.

REIS, C. F. de B. Os Efeitos do Investimento Público sobre o Desenvolvimento Econômico: análise analise para a economia brasileira entre 1950 e 2006. UFR,,2008a. Disponível em: http://www3.tesouro. fazenda.gov.br/Premio_TN/XIIIpremio/qualidade/2qualidadeXIIIPTN/_CR.pdf. Acessado: Abril de 2015

REIS, A. F. Investimento público em infra-estrutura e privatizações. In: Anais do Encontro Nacional de Economia, 36., 2008, Salvador, BA. Salvador: ANPEC, $2008 \mathrm{~b}$.

ROCHA, C.B.; MORATO, R. A. Gestão Portuária: Análise Comparativa entre Modelos Internacionais e Propostas ao Modelo Atual Brasileiro. Disponivel em:< http://aplicativos.fipe.org.br/enaber/pdf/66.pdfs. Acessado: Jul.2013.

SEP. Secretaria de Portos. Disponível em:< hitp://www.portosdobrasil.gov.br/>. Acessado: Junho. 2013. WORLD BANK , Connecting to Compete, 2007,2010,2012, 2014. Disponivel em http://pi.worldbank.org/. Acessado: Abril de 2015. 
